This item was submitted to Loughborough's Research Repository by the author.

Items in Figshare are protected by copyright, with all rights reserved, unless otherwise indicated.

\title{
Archers' experiences of target panic: an interpretative phenomenological analysis
}

PLEASE CITE THE PUBLISHED VERSION

https://doi.org/10.1080/2159676X.2019.1599061

PUBLISHER

(c) Taylor \& Francis

VERSION

AM (Accepted Manuscript)

PUBLISHER STATEMENT

This is an Accepted Manuscript of an article published by Taylor \& Francis in Qualitative Research in Sport and Exercise on 31 Mar 2019, available online: https://doi.org/10.1080/2159676X.2019.1599061

LICENCE

CC BY-NC-ND 4.0

\section{REPOSITORY RECORD}

Prior, Erin E., and Janine Coates. 2019. "Archers' Experiences of Target Panic: An Interpretative Phenomenological Analysis”. Loughborough University. https://hdl.handle.net/2134/37451. 


\section{Archers' Experiences of Target Panic: An Interpretative Phenomenological Analysis}

Erin E. Prior and Janine K. Coates

School of Sport, Exercise and Health Sciences, Loughborough University, Loughborough, UK

\section{Corresponding author:}

Dr Janine Coates,

School of Sport Exercise and Health Sciences,

Loughborough University,

Loughborough,

LE11 3TU,

UK

$+44(1509) 226442$

j.k.coates@1boro.ac.uk

\section{Biographical note:}

Erin Prior is a trainee Sport \& Exercise Psychologist currently undertaking her Stage 2 accredited training. Her research interests include performance blocks in sport, with a focus on target sports; and the promotion women's participation in sport.

Dr Janine Coates is a Lecturer in Qualitative Research Methods at Loughborough University. Her research expertise relate to education, disability sport and inclusion.

\section{Funding:}

This research was conducted without funding. 


\section{Archers' Experiences of Target Panic: An Interpretative Phenomenological Analysis}

Performance blocks are a common problem affecting athletes in a multitude of sports and can prevent accurate execution of sport-specific movements, significantly impacting an athlete's career. However, little is known about performance blocks in archery, commonly referred to as 'Target Panic'. The present study used Interpretative Phenomenological Analysis (IPA) to analyse accounts of seven archers impacted by target panic to gain an in-depth insight into their experiences. The findings show target panic to be complex, where it is preceded by events leading the archer to focus too much on the outcome of their shots, forcing their desire to take control. This leads to a loss of control over the shot and the characteristic effects of performance blocks are experienced. Finally, this results in archers taking steps to regain control over shot execution and overcome the anxious tendencies associated with target panic. These novel findings add weight to the existing performance blocks literature by illustrating the similarities and differences between target panic experienced by archers and performance blocks in other sports. It concludes with recommendations for the management of performance blocks in archers.

Keywords: archery, performance block, lived experience, anxiety, control

\section{Introduction}

Elite athletes execute well-practiced skills with minimal attention or conscious effort (Bennett, Hays, Lindsay, Olusoga \& Maynard, 2015), however, they experience significant demands which can impact their personal and professional wellbeing (Rice, Purcell, De Silva, Mawren, McGorry \& Parker, 2016). These demands can trigger anxiety and lead to performance blocks (Bennett \& Maynard, 2016). Performance blocks are the sudden loss of ability to perform a skill (Crampton \& Adams, 1995), which can significantly impact an athlete's career. This phenomenon is prevalent within several sports including golf (Bawden \& Maynard, 2001; Bennett et al., 2015), hurdling (McFarlane, 1990), and trampolining (Clarke, Sheffield \& Akehurst, 2015), yet 
performance blocks research is in its infancy, and little is understood about its aetiology in target sports like archery, which is the focus of this paper.

\section{Performance Blocks}

Performance blocks are defined as a psychological disorder of control, involving the loss of ability to carry out specific movement patterns, often resulting in involuntary jerks, spasms, tremors, and freezing (Bawden \& Maynard, 2001). They are often referred to as 'the yips' (Smith, Adler, Crews, Wharen, Laskowski, Barnes, et al., 2003, Clarke, Sheffield \& Akehurst, 2015); and lost movement syndrome (LMS) (Bennett et al., 2015). In archery, they are referred to as 'target panic' (Kidwell, 2004). Whilst terminology differs, characteristics of performance blocks are similar for different sports. Clarke, Sheffield \& Akehurst (2015) state that performance blocks are characterised by physical symptoms (dystonia) and psychological symptoms (anxiety / 'choking'), and attempts have been made to understand them through exploration of attentional processes relating to skill execution under pressure (Baumeister \& Showers, 1986; Baumeister, Hutton \& Cairns, 1990; Eysenck, Derakshan, Santos, \& Calvo, 2007). Eysenck et al (2007), for example, argue that pressure related to performance creates a distraction that shifts attentional focus to task-irrelevant cues, such as concerns about the situation and its consequences. This shift of focus changes single-task performance into dual-task situations where execution of the task and anxiety regarding the situation compete for attention, negatively influencing performance. Alternative explanations suggest that pressure related to performance increases self-consciousness and anxiety regarding performing effectively, which increases the attention given to skill processes and their step-by-step control (Baumeister, 1984; Lewis \& Linder, 1997). Thus, focussed attention on execution may disrupt well-learned, proceduralised 
performance and trigger performance blocks (Baumeister, 1984; Lewis \& Linder, 1997). Fundamentally, these theoretical stances agree that performance-related behaviour is underpinned by the way in which pressure to perform is processed by athletes. These arguments are supported by the recent model of 'yips' classification proposed by Clarke et al (2015), that suggests performance blocks can be experienced differently by different athletes in relation to their physical and psychological symptomology, but crucially is dependent on the pressure to perform in a given environment. While the Clarke et al (2015) model goes some way toward classifying yips in relation to physical and psychological symptoms in line with the theoretical perspectives outlined above, they indicate that there is still uncertainty with regard to the aetiology of the yips, and that further research is needed to better understand the predictors associated with performance blocks. Further, in the development of their model, Clarke et al reviewed existing performance blocks literature, and noted ony two studies have examined the yips and yips related-behaviour qualitatively (see Bawden $\&$ Maynard, 2001; and Philippen \& Lobinger, 2012). Rather, the majority of the research from which this model was developed drew on quantitative, predominantly psychometric testing. Given uncertainty surrounding the aetiology of performance blocks in sport, particularly target sport, as highlighted by Clarke et al (2015), this study aims to further develop understanding about performance blocks in archery and the impact they have on athletes. Understanding the specific contexts in which performance blocks occur, and how athletes in different sports might experience these, is important for the future development of psychological intervention to both help prevent and treat target panic.

Further, while theoretical models of performance blocks suggest pressure to perform might be a contributing factor in their development, performance anxiety is 
also thought to play a significant role in both triggering and exacerbating performance blocks, and this may be influenced by the pressure to perform in both training and competition contexts (Bennett et al, 2015). Although athletes need adequate preparation time before training and competition, this may encourage inward-thinking, perceptions of inadequacy, increased anxiety and fear of failure (Bawden \& Maynard, 2001; Singer, 2002). Singer (2002) argues that a skill or event that is perceived as particularly meaningful can result in increased anxiety and arousal levels which may lead to a switch from unconscious to conscious processing. As a result, an athlete's thoughts may shift from focusing on performance enhancement, toward self-critical perceptions about their performance (Jackson, Ashforth \& Norsworthy, 2006) The shift towards conscious processing can undermine fluidity and automaticity of executed skills, triggers performance blocks (Maxwell, Masters \& Eves, 2000).

While literature provides some insight into the antecedents and consequences of performance blocks, this area of sport psychology is in its infancy and there are calls to better understand the characteristics of performance blocks in order to develop robust theory surrounding the disorder (Clarke et al, 2015). Moreover, research indicates that performance blocks in target sports, such as archery, can have a serious and negative influence upon athletic careers (Marquardt, 2009; Weiss \& Reber, 2012). Although specific prevalence data relating to target panic in archers is not currently available, it is suggested that in golf, performance blocks can affect between $28 \%$ and $52 \%$ of professional and amateur athletes, often with detrimental impact to their future performance (Dhungana \& Jankovic, 2013). Indeed, a New York Times article about target panic suggested that the disorder could affect up to $90 \%$ of archers at some point in their career, but that the problem is so sensitive that it has become taboo in archery circles (Thomas, 2008). This further reinforces the need for context-specific 
understanding about performance blocks in archery, as well as the need to open discussion about target panic to break down barriers toward seeking support. Different sports promote different strategies to overcome performance-related issues, but without a detailed understanding of how and why archers are experiencing target panic, effective and evidence-based interventions to support them cannot be reliably developed.

Given the negative influence of performance blocks upon athletic career progression (Marquardt, 2009), the impact on athlete well-being and the lack of literature exploring target panic specifically, it is necessary to further understanding of this topic area. Therefore, this study aimed to explore the experiences of target panic amongst archers. Specifically, it aimed to develop a more robust understanding of the potential antecedents to, manifestations of and coping mechanisms for managing target panic. Therefore, the research question guiding this study was 'how do archers experience and conceptualise target panic?'.

\section{Methodology}

\section{Design}

This study was underpinned by epistemological constructivism, which is the understanding that individuals construct meaning through the experiences they have and they ways they engage with the world. Given the aim of this research was to understand archers' experiences of target panic, this study employed Interpretative Phenomenological Analysis (IPA). IPA is an ideographic approach which adopts a hermeneutic, phenomenological framework, suited to research where the experiences of individuals, and the meaning these experiences hold for the individual, are sought 
(Smith, Flowers \& Larkin, 2009). It aims to explore in detail how participants make sense of their personal and social worlds (Pietkiewicz \& Smith, 2014).

IPA is underpinned by a philosophical commitment to phenomenology (Smith, 2004). Phenomenology is concerned with lived experience where it is acknowledged that there is no fixed reality or truth, but rather that human experience is subjective, fluid and constructed by individuals who interpret and develop their social understanding through experience. This relates to "intentionality" which explores the relatedness of human consciousness to an 'object' (Crotty, 2009; Smith et al, 2009). Through this, we seek to better comprehend how archers make sense of their experience of target panic by focusing on their personal descriptions of that experience.

Further, IPA recognises that interpretations relating to experience are coconstructed socially through interactions with others - referred to as double hermeneutic (Smith, 2004), such that while the "participant is trying to make sense of their personal and social world; the researcher is trying to make sense of the participant trying to make sense of their personal and social world" (p.40). To achieve this, a process of critical and reflexive analysis was undertaken. Through engaging with descriptions of experience in a rigorous, interpretive manner, a better understanding of individuals cognitive and affective processes can be ascertained.

Given this study's aim to better understand the experiences of target panic amongst archers, IPA was deemed the most appropriate methodology. Specifically, the ideographic and interpretive approach taken in IPA allowed for meaning to be drawn from the descriptions of target panic provided by participants furthering understanding about the aetiology of target panic, and the methods used by archers to overcome these performance blocks. 


\section{Participants}

Purposive sampling using a snowball sampling strategy was employed.

Participants were recruited if they were over the age of 18, participated in archery and had current or previous experience of target panic. As all of the participants were aged over 18 , they are all categorised as senior archers. The senior archery category has a wide age range from 18 upwards. At the time of the study, all participants were actively engaged in archery at competing in their respective level of competition.

There was also variation in terms of the level of archery the participants engaged in. The participants were a mix of club, county, national and international level archers. For reference, club level archers tend to participate without competing or compete at various local clubs; county level archers compete at various local clubs but also represent their home county at various team events against other counties that are within their region; national level archers compete for England against other home nations (Scotland, Ireland and Wales); and international archers compete for Great Britain against other countries in the world at international events such as World Championships and European Championships. The fact that the participants varied in their ability and level at which they competed suggests that target panic can occur for any archery, regardless of their experience or skill level.

Initial recruitment was via an advertisement on an archery social media website, and participants were encouraged to signpost peers who might have experienced target panic to the study. Seven participants (male, $n=3$; female, $n=4$ ) participated. Table 1 provides summary information about participants. Note that pseudonyms have been used to protect participant identity. 
Table 1: Participant Summary

\begin{tabular}{|l|l|l|l|}
\hline \multicolumn{1}{|c|}{ Participant } & \multicolumn{1}{|c|}{ Gender } & Length of Time & \multicolumn{1}{c|}{ Level Achieved in } \\
& & Participating in Archery & \multicolumn{1}{c|}{ Archery } \\
\hline David & Male & 3 years & Club Level \\
\hline Alex & Male & 10 years & Club Level \\
\hline Julia & Female & 11 years & County Level \\
\hline Trevor & Male & 18 years & National Level \\
\hline Fran & Female & 8 years & National Level \\
\hline Jessica & Female & 9 years & County Level \\
\hline Valerie & Female & 11 years & County Level \\
\hline
\end{tabular}

\section{Data Collection}

Prior to participation, all participants were provided with detailed study

information and asked to provide written consent. Participants then took part in a semistructured interview. Semi-structured interviews are considered to be an exemplary method for IPA and are used due to their suitability for exploring individuals' experiences, knowledge and thought processes in a flexible manner (Sparkes and Smith, 2013). A 10item semi-structured interview schedule was used to prompt discussion surrounding how participants believed their target panic developed, how their target panic manifested itself, and any strategies the participants used to overcome the difficulties which arose from their target panic. These questions and prompts were informed through a significant reading of literature surrounding performance blocks and the primary researcher's understanding of archery and target panic to create archeryspecific questions. However, these were just used to guide participants where necessary. Participants were given the freedom to direct the discussion relevant to their own 
experiences Interviews lasted between 33 minutes and 65 minutes. Interviews were transcribed verbatim and analysed using IPA protocol (Smith et al, 2009). Please see Figure 1 for example questions used in the interviews.

\section{Figure 1: Interview schedule}

\section{$\underline{\text { Interview Schedule }}$}

1. Can you tell me how you got into archery?

a. How long have you been participating in archery?

2. How would you define target panic?

3. What has your experience of target panic been like?

a. How has target panic influenced your shot/shot sequence?

4. How did/does target panic make you feel (emotionally, mentally, and physiologically)?

5. What would you say could be the cause of target panic for you?

6. Would you say you experienced any significant events (inside or outside of archery) prior to the onset of target panic?

a. If so, what influence would you say that experience had on your target panic?

7. What influence has target panic had on your life (performance or otherwise)?

8. Have you attempted to address target panic? If so, how?

9. Have your attempts been successful or unsuccessful?

10. What would your advice be for other archers experiencing target panic?

\section{Data Analysis}

Interview transcripts were initially analysed by the lead author. Analysis

followed the process outlined by Smith et al (2009) which allowed for immersion within the data and enabled an in-depth understanding of the views and experiences expressed by the participants. Each transcript was read multiple times to establish familiarity with the data and gain a sense of participants' experiences. Descriptive comments were then 
made regarding interesting comments or early impressions of significant data. This allowed for significant aspects of each interview to be captured. As a result, initial themes were identified and labelled, and then clustered based on their similarity. Superordinate themes and sub-themes were then developed within each case. At this stage, the co-author was given access to the data. Taking on the role as an auditor and critical friend, the co-author examined the coding and themes alongside the data to confirm or question the interpretations being developed. Based on these in-depth analytical and reflexive discussions, the first author re-visited the analysis, examining the data on a case-by-case basis to develop a refined list of themes for each case.

To catalogue how the themes were represented within the data, a table was created containing relevant excerpts from each transcript. Each transcript was analysed independently, however particular attention was paid to any repeating patterns, similarities or distinct differences across the data set.

Once interpretation of all transcripts had taken place, a thematic map of superordinate and associated sub-themes drawn from all the transcripts was created to aid final selection (See Figure 2). This involved merging themes that were conceptually similar and removing those that were less substantial across the data set. Illustrative quotes from the interviews were linked to all the remaining themes. 
Figure 2: Thematic map

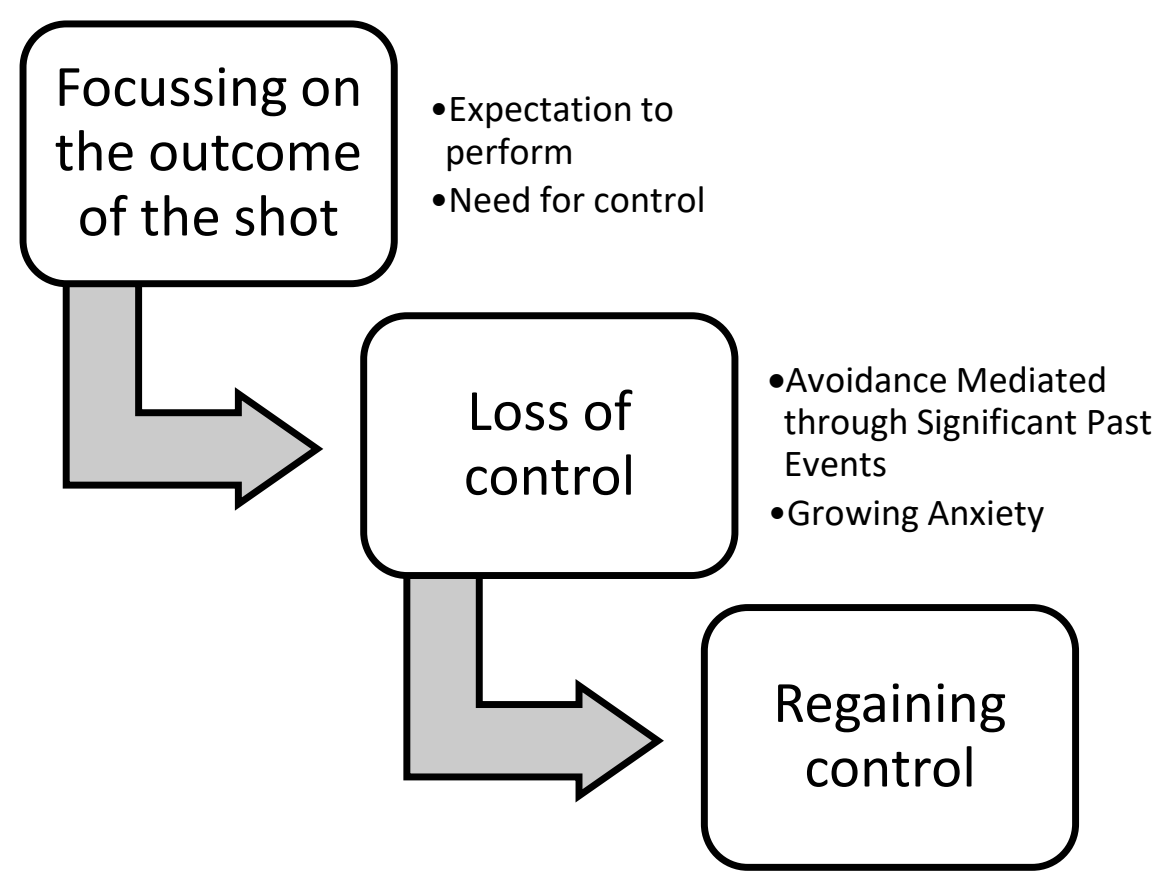

\section{Establishing rigor:}

It is worth highlighting that the first author has actively participated and competed in archery for over a decade; and has experienced target panic. This experience along with discussions with peers and fellow competitors led to an interest in the topic area and the development of the research question. Given how close the experiences of the participants might be to the experiences of the interviewer, it was necessary from an early stage to develop mechanisms to establish rigor and ensure that the experiences of the participants were given primacy. This was achieved in several ways.

First, the first author adopted bracketing (Smith, Flowers \& Larkin, 2009) to better understand how her own preconceptions surrounding target panic might influence the research process. This was done alongside the co-author, who is an experienced qualitative researcher with no personal experience of archery or of performance blocks. During initial project meetings, open discussions were had about the first authors personal experiences, how they influenced the decision to pursue the research and how 
these prior experiences might influence the design of the research and the interpretation of findings. These reflexive conversations allowed the co-author to gain a grounded understanding of the first authors experiences, and to critically question decisions that were made throughout the research to ensure trustworthiness in the data collected and the interpretations made. In this way, the co-author acted as a critical friend (Smith \& McGannon, 2017) both in the design of the research, and the analysis of the data. She assisted with the development of the interview schedule, assessed the quality of the initial interviews to ensure participants were not being led, reviewed the coding of transcripts and monitored theme development within and between cases to ensure credibility against the data.

\section{Results}

Analysis of the data revealed three recurrent superordinate themes and the subordinate themes which they incorporate. The themes related to the participants' conceptualisations of the onset of their target panic as a focus on outcomes; the manifestation of target panic as a loss of control; and the strategies they utilised in regaining control of their performance in archery.

\section{Focussing on the Outcome}

This theme explores how all participants perceived the onset of their target panic to be attributed to a focus on the outcome (score) of each shot they took, which relates to both their expectation to perform and their desire to be in control. Alex describes this:

"I could feel it [target panic] coming on especially when you're scoring and you're thinking you know, I need to get an ' $\mathrm{X}$ ' or a $\mathrm{PB}$ - that can be when it starts to set in... So when you're starting a round for instance, there isn't that pressure. You tend to - with me, the scores earlier in the round are better than 
they are at the end because I start thinking about, oh I need to get this, I need to get that."

As demonstrated here, participants related this focus on the outcome to their expectations of themselves and others, which increased feelings of anxiety and pressure to perform. This way of thinking also led to feeling a greater need to take full control over the shot diminishing the automatic reflexes they would usually encounter when making a shot. These findings were recurrent in the data and consistently related to the desire to achieve a specific outcome. Thus, this theme encapsulates two subordinate themes - expectation to perform; and the need to take control.

\section{Expectation to Perform}

This sub-theme relates to participants' focus on a specific outcome or achievement that is developed from an intense desire to meet the expectations that they set themselves or to appease the expectations of others. Participants were acutely aware of the expectation's others might have of their performance. Being able to achieve these expectations led to a greater focus on outcomes, and a greater self-awareness when taking shots. This was something particularly pertinent for David:

'Much to the surprise of most people, it [target panic] always happens with the largest targets... There's a general consensus that the larger the target, the easier it is to hit and sometimes, especially with longbow where accuracy is not always the highest thing in your shooting, it can be quite a daunting thing because you can have a $122 \mathrm{~cm}$ target out on the boss at 60 yards and there's this expectation that it's a big target, you should be able to hit it, so if you don't - or if in the past you've not been able to hit it, that does then produce this sort of, you're standing on the line, you're thinking - you're looking at it even - and you're thinking, 'oh no, what if I miss? What if I'm short? What if I'm over? What if everyone is 
looking at me? What will they think?'... I'm generally more likely to mess up a shot because I'm either overthinking or I'm literally panicking, but I think the biggest effect for me is physically, there's this tendency to want to, not creep away from the target as such, but it has the effect that you want to - you want to draw, but then that slight seed of doubt comes into your mind so you might not say bring the string all the way back to your face. Or you might overdo it and you might overcompensate and you end up adding complexity onto complexity until you eventually think 'I can't do this anymore'... on the field if you're being watched, there's this feeling that you must live up to everyone else's expectations, and if you don't there's that feeling that you're not adequate and that you're wasting your time.'

Here, David describes the effect that the expectations of others judging his performance has on his confidence to take an accurate shot, and in turn, the physical manifestation of target panic which prevents him from making an accurate shot. Reflecting on his experiences, he closely ties his self-esteem to his performance, and where he is unable to perform to the expectations of others, his self-esteem diminishes, and with this, his physical ability and motivation to take a shot. He relates his experience of target panic with avoidance, as if through avoiding the shot will also avoid the negative judgements of those watching him. Consequently, target panic is significantly demoralising and impacts his self-worth.

This cycle of loss of confidence manifesting into physical blocks and ultimately a loss of motivation was evident in the experiences of other archers. Julia spoke of a similar experience in terms of not living up to expectations, particularly when shooting at longer distances: 
'I wasn't successful in my view and my scores weren't improving so - and then I wasn't enjoying it and then I felt stupid that I wasn't doing very well and I probably felt like people were looking at me and thinking "ooh you're not getting very good scores", so I just lost confidence with it and ground to a halt with it in the end... I honestly don't think I did aim properly because I think sometimes my husband would say, 'I can't understand why your arrows are going in the grass, where are you actually aiming when you're aiming?' and in my head I'm thinking I'm aiming at the gold but actually in reality I think I was sometimes aiming off the target.'

Like David whose target panic was more severe for larger targets, Julia's target panic manifested predominantly with shots at longer distances. For both, there was the acknowledgement that they were less successful in achieving these shots. This led to the internalisation of perceived failure relating to the expectations of others and their judgements, a loss of confidence, and ultimately the onset of target panic and decreased motivation to perform.

Expectations from others (e.g. knowledgeable spectators, family members, sponsors) were commonly discussed in the interviews. Fran, for example, discusses the expectation in relation to keeping her spot on the national team. Here she refers to a 'clicker'. A clicker is a device on a bow that ensures that the archer pulls the string back the same distance each time they execute a shot - this aims to help the archer be more accurate. The clicker rests on top of the arrow, and when the archer pulls the string back the correct amount, the clicker makes a 'click' sound. This signifies to the archer that they can shoot their arrow:

'I sort of do the sort of pointing at the middle but I used to aim off to the left and that was me not realising I was doing it, but I sort of aimed off to the left and felt 
more comfortable shooting that way. And then I've also had it where I've come up and not been able to come through my clicker. I think that pressure to get good scores then caused that and I think that came heavily from GB where I was training a lot, and they were like "you need to get this score otherwise you'll be kicked off."”

She acknowledges how the added pressure to perform so that she can continue to shoot for GB led to her inability to perform as expected. Here she details how this pressure resulted in her aiming off-target, and not being able to pull through her clicker. As Fran feels unable to come through her clicker, she is unable to make the shot, which she attributes to the pressure to perform to expectation.

Indeed, recognising, or perceiving that others might expect something beyond what the archer may feel able to achieve at the time added pressure and led to participants setting high expectations for themselves, creating anxiety. This appears to contribute to the development and maintenance of target panic whereby archers set themselves goals which focus heavily on the outcome of each shot to appease expectations, but where the confidence to achieve these outcomes is low. This demonstrates that the perceived expectations of others might trigger the onset of target panic, but particularly for shots where the archer already doubts their own performance. Participants also talked about the expectations they set for themselves. They described a similar focus on performance outcomes where performance was going well. Trevor describes how a focus on results can occur once an archer starts to progress within the sport, and how this too can lead to the onset of target panic:

'For me [target panic] is performance driven. You've started shooting and you're getting on alright and then suddenly it's like, you want to shoot a bowman score, you want to show progression, 'ooh I want to shoot a certain 
score' and you move into a performance focus and then instead of wanting to make a decent shot, it becomes "right I must shoot a ten". And at that point, your focus isn't this side of the line, it's all the way down there and you're trying to control everything too much, it's like 'I'm in charge, I can control everything that's going on'... I think at the end of the day, for a lot of people target panic doesn't come down to being scared you're going to put your string into your arm or you'll be physically injured - it's target panic. You're scared of the target and the possibility of poor results.'

This extract suggests that as an archer improves, the desire to show progression increases, and thus, for Trevor, this resulted in setting himself high expectations for future performances. Specifically, he wished to achieve a 'bowman score', which refers to a classification that is awarded after hitting a certain score three times. In his interview, he also compares his performance and preparation to successful elite archers, acknowledging that increasing the amount of control he wishes to have over his shot, might not be achievable for 'the average archer'. Like David and Julia, Trevor associates his target panic with a focus on outcomes. This led to increased anxiety surrounding performance and triggered his target panic

This sub-theme illustrates how both internal and external expectations might shift an archer's focus from making the best-possible shot to achieving a specific outcome. This shift in focus toward the outcome results in increased pressure to perform and anxiety, manifesting itself in the physical symptoms of target panic. While expectations seemed to be significant antecedents to the onset of target panic for the participants, this was often coupled with the increased need to control each shot. This is explored in the next sub-theme. 


\section{The Need for Control}

This sub-theme explores the ways in which archers managed the anxiety relating to achieving expectations, which for several of the participants led to the archers attempting to increase their control over their shots. The desire to be in control led to physical symptoms of target panic, reducing the impact and ability of the archer to achieve the intended outcome. Julia explains her difficulty trying to control her anxiety by using a clicker::

'I just couldn't get to my anchor point... I remember thinking that if I could trick my mind into thinking if the clicker was there that as long as the clicker didn't go off, then I could hold it to my anchor point... I always found the clicker a struggle. I was forever moving it, now I think about it, constantly moving it forward. Probably because I wasn't executing the shot, maybe I wasn't expanding properly and feeling confident. I remember something would happen with my fingers as well. I remember I was at a competition near the end of shooting and somebody having to let me use Compedes to put on my fingers. I must have squeezed in the wrong place and they went white and really sore, so in the end it became impractical to shoot. I'd feel grumpy because I couldn't get very good scores and a bit stupid when other people were there... I think in the end, I just gave up.'

When defining target panic, Julia describes it an inability to aim or focus on the gold. She then overcompensates when trying to find her anchor point and uses mental imagery in relation to the clicker to control this. However, for her, this increases her anxiety, disabling her shot. To manage the anxiety, she ineffectively changes the way she shoots, leading to physical injury. Further, she explains how the presence of others exacerbated the issue and she relates this to a lack of confidence to take an effective 
shot. Needing to control elements of the shot to overcome anxiety was something discussed by other participants, some of whom relate the desire to control shots to feelings of obsession. Trevor explains:

‘... you're trying to control everything you possibly can. For me, it mostly manifests itself through aiming, so where you're trying to put your dot right in the middle, because if it's aimed there then it's going to go there right? Actually, not so much, but it's that sort of - you can't make the shot go, and you can't make a clean shot because you're trying to aim obsessively...I can manage the yips better with a compound because I can remove all the control elements that I can put in and it just comes down to, "right I've taken my thumb off the peg and here we go". It's kind of that controlled reckless abandon.'

Trevor's target panic manifested more frequently when using a recurve bow. The removal of the individuals' ability to control the shot in minute detail, such as when shooting compound, alleviated the target panic. Interestingly, for several participants, target panic was more of an issue for one bow style over another, and for most, the issues manifested more when trying to control movements to achieve a better aim. This highlights that target panic is related to a desire to achieve a specific outcome, or meet some expectation, and manifests through overcompensation in attempting to control aim. This in turn leads to the physical manifestation of a performance block. In this instance, target panic manifests as a loss of control, which is explored in the following theme.

\section{Loss of Control}

This superordinate theme captures the various ways in which target panic manifests, however one commonality is the loss in control the archer has over their shot 
sequence. Lost control was reflected for all participants as a key symptom of target panic, which impacted the physical ability to aim and shoot accurately and reflected an inner conflict between the archer's intentions and physical capability. For some, this resulted in not being able to release the string and for others, not being able to reach the anchor point (a point of reference for shooting).

Participants explored their loss of control during target panic, relating these experiences to significant prior events which exacerbated anxiety; and ultimately led to avoidance in making shots. These will be explored within the subthemes Avoidance mediated through significant past events and Growing anxiety.

\section{Avoidance Mediated through Significant Past Events}

This sub-theme relates to significant events that have occurred within the archers' lives, within and outside of archery, which may be an antecedent to the onset of their target panic. Participants reflected on how these experiences increased their desire to take control during high-anxiety events, like when shooting during competition. Several participants highlighted significant past experiences which created anxiety whilst participating in archery, whether consciously or sub-consciously, which they relate to the onset of target panic. David describes how, for him, anxiety relating to sudden, loud noises triggers his target panic:

'... in the club there have been incidents, I mean sometimes it's been a case of not - and it's going to sound very silly - but not nocking arrows correctly, so when the shot is released, there's a big clatter of sound and the arrow dropping to the floor. And of course it's a bang, it's a sudden noise, it's a shock and your body will naturally want to cringe and walk away from that and avoid situations. That can sometimes create the issue of target panic on the line because you try 
not to produce the same effect... It has happened many times. There is a tendency for you to subconsciously or unconsciously avoid said situation. So, it might be shown in cases of not drawing back to the chin, or even a tendency to not even want to shoot - you've got the thing of constantly having to draw, put down, draw, put down again.'

Here, David expresses a dislike for loud, sudden noise which he relates to equipment malfunction. The anticipation of recreating this noise, and thus experiencing equipment failure, leads to feelings of anxiety. Consequently, he avoids actions which may cause similar reactions, inhibiting actions which might produce a successful shot, or avoiding a shot altogether. This loss of control needed to shoot effectively is a response reflex to avoid unpleasant situations whilst shooting. Further, David goes on to explore how childhood events may have resulted in his performance block. In this particular instance he discusses when he used to play with a golf club and golf ball in the house which resulted in him being reprimanded by his parents:

'I think one of the main external incidences will be just generally the type of household I've grown up in... Like I said, with the golf club, would've meant it would've - wouldn't say gone flying into the house, but might've bounced off a window or something and that would've meant my getting shouted at. So, my brain is associating it [target panic] with not getting shouted at, so my brain is avoiding situations even though it's not going to happen, I would get shouted at or moaned at.'

The fear of displeasing others had a direct impact on David's ability to overcome feelings of anxiety when shooting. This was a result of an unconscious attempt to avoid negative consequences relating to making a poor shot - whether this be the disappointment of others or fear of equipment failure. 
While for David, the events which impacted his performance were unrelated to archery, for other participants, specific experiences whilst practicing archery resulted in increased anxiety in relation to shooting, and an associated loss of control in making the shots. Jessica experienced significantly traumatic events which preceded the development of target panic. One occurred when her bow malfunctioned resulting in injury, impacted on her ability to stay calm under pressure when shooting, resulting in target panic. Here she explains how her bow malfunctioning had a particularly significant impact on the development of her target panic:

'Your conscious and your subconscious mind are connected, and something comes along like a traumatic event and it sort of splits them or cracks them. It breaks that connection, so your brain is then thinking about that [the traumatic event] and the panic so then it affects the archery side of the panic. And I'm surprised about how much that affected me because I didn't think it would. But basically, that panic situation of pulling up, holding it and then getting the panic again, that was triggered again after the traumatic event... I remember when I did shoot again after that, it did take a while because of the fear of it happening again - of it hitting me in the face. And it took me quite a few months to finish losing the bits of teeth out of my gum because it went straight up my nose - so that was quite a nasty one.'

Jessica associates anxiety and fear with the traumatic events she has experienced. She describes the shift in her thinking and how her subconscious memories creep into her conscious, moving her focus away from the task at hand and redirecting it to the feelings she experienced during the events. This change in thinking when shooting leads to loss in the ability to control focus to take an accurate shot, which 
triggered performance blocks. Like David, this relates to a fear or anticipation that the negative experience might reoccur.

Several participants shared these sorts of feelings and experiences, where memories of a prior, sometimes seemingly insignificant event, resulted in rising feelings of anxiety whilst aiming and shooting. For many, this inability to control focus, led to increasing feelings of panic. These feelings were then managed through avoidant behaviours. Several participants reflected on their tendency toward avoidant behaviours. This included purposefully avoiding reaching their anchor point, not releasing the shot, or not aiming at the gold. Participants felt little control over their ability to override these avoidant tendencies. David explores this:

'For me it's a case of not bringing it back all the way. A tendency to cringe from the shot to get it away as quickly as possible, to get rid of the anxiety." For David, the tendency to avoid aspects of his shot was a reaction to the growing anxiety he felt in relation to past events (see discussion above) which carried negative emotional connotations; which set him in a cycle of anxiety, avoidance, and poor performance. This appeared to amplify feelings of a loss of control and the effect of his target panic.

Julia shared a similar experience, where previous experiences in archery - this time in relation to not performing well in longer distance shooting and perceptions of judgement from others - led to avoidant behaviours. She reflects on this:

'In my head I'm thinking I'm aiming at the gold but actually in reality I think I was sometimes aiming off the target. Whether that could be suggested that that was a non-conscious target panic, I don't know. But I think I just got to the point where I was just shooting arrows and wasn't really focusing on the aiming... I just think I got annoyed with myself that I couldn't do long distances in the end.' 
Here, Julia suggests that despite thinking she was aiming at the gold, that she may have been avoiding the gold and aiming elsewhere, and again, like David, she did

not feel in control of this behaviour. She refers to this as an 'unconscious target panic'; something she was not aware was happening at the time, but on reflection seemed apparent to her. This was common, where participants were not aware of their avoidant behaviours at the time, but that retrospective reflection allowed them to better understand their experience. This is important for better understanding the cognitive manifestation of target panic as related not only to prior experience, but also to behaviour which feeds the feelings of anxiety relating to target panic. The next subtheme explores these underlying feelings of anxiety in more detail.

\section{Growing Anxiety}

For many participants, feelings of anxiety underpinned their target panic experiences and were often related to issues relating to performance (or lack of confidence to perform), negative previous events, or a general fear of failure. Participants often articulated these feelings of anxiety as a rising panic which prevents or blocks the desire to perform, thus a loss of control over skill execution. Julie describes this sensation:

'I want to do it (shoot), but I feel like something inside me doesn't want me to do it. I actually feel anxious. I can feel a panic rising up in me like an anxiety that doesn't want me to look at the gold, which is ridiculous. It's crazy really.'

This extract highlights Julia's approach-avoidance conflict of wanting to shoot, but experiencing anxiety, not unlike a survival instinct, which prevents her from executing her shots. This indicates that target panic might manifest as a loss of control over both cognition and behaviour, as seen by Julia's inability to execute the shot - 
despite her desire to do so - due to anxiety. Julia's anxiety stems from past experiences that have induced fear when executing her shots. She also suggests that her anxiety is 'crazy'. This highlights the involuntary nature of her anxiety, but also her intolerance towards it which may be due to her high expectations of herself.

The manifestation of target panic as a loss of cognitive and behavioural control was mirrored in the experiences of other participants. Jessica, for example states:

'There's quite a few shoots where I would start, and I'd be fine and then I'd pack up because I'd feel unsafe in what I was doing.'

Like Julia, Jessica's past experiences led to a growing anxiety in relation to her safety while shooting, preventing her from taking shots. For her, increasing anxiety surrounding risk of injury seemed to be disable her when executing shots. However, for some other participants, anxiety was not rooted in past experience. Trevor explains how his anxiety was rooted in his ability to perform effectively.

'What usually happens is that I find myself under pressure and the voices in your head start talking and I find myself aiming a little bit right, mid-nine at 2 o'clock.... I would get to sort of doing quite well and I would get out of my comfort zone and that's usually when something would start to go wrong.' Trevor describes 'hearing voices' which ineffectively coach him through each shot as his anxiety surrounding his performance grew. This was particularly true when Trevor moved from what he calls his 'comfort zone', especially when he has previously been performing well. This causes him to aim in a different place highlighting potential avoidant behaviour and shot control difficulties on an unconscious level, perhaps by aiming less accurately, Trevor feels this may dissipate his anxiety and return him to his comfort zone - performance at a lower level of competition where he feels more confident in his ability to succeed. Furthermore, Trevor's anxiety may be a result of his 
focus on his score, which consequently exacerbates this performance block. This indicates that a growing anxiety surrounding performance, whether related to prior negative experiences, or to a focus on shot outcomes, might lead to increasing performance blocks and the manifestation of target panic. This relates to a loss of cognitive and behavioural control over performance.

\section{Regaining Control}

This superordinate theme relates to how the archers cope with their target panic and regain control over their technique. Participants discussed the range of coping mechanisms they use which included justification, practical techniques and, for one participant, hypnosis. David was one participant who attempted to make sense of his unsuccessful shots by justifying them in order resolve target panic symptoms:

'A lot of the times it's just me telling me to suck it up and get on with it because you are shooting longbow, you will miss shots, it's a fact of life, but it doesn't necessarily mean you're a bad archer because everyone misses shots now and again.... I do find sometimes, telling myself is not enough.'

David's attempt to rationalise missing shots as part of the process of developing as an archer more generally, may serve to minimise his anticipation and fear of scoring unsuccessfully. He also attempts to avoid internalising his perceived failure, by generalising his feelings and experiences beyond his own. This method for coping with target panic, however, does not appear to work effectively for David, perhaps due to the self-critical nature of this way of coping. David reflects on his own shortcomings through his inability to 'suck it up', highlighting low confidence in his ability to overcome the anxiety related with his performance. This was also true of Julia, who also experienced internal conflicts alongside a self-critical attitude. 
'I think maybe I could be mentally strong and think "come on, get your act together, stop doing this and just do it.",

This quote reflects Julia's impatience with herself, much like David. Seemingly, target panic inspires frustration, with archers blaming themselves for their difficulties. However, these punishing mentalities do little to help the archers cope with their target panic.

Practical methods for coping with target panic included 'blank boss'. This involves shooting at a blank target with no target face to aim at (a target face in this instance typically refers to yellow, red, blue, black and white coloured rings that archers aim at and try to hit). Several participants deemed this practice ineffective despite its frequent use in coaching, as archers noted that when shooting 'blank boss' they could successfully overcome target panic, but when a target face was used again, their target panic returned. In relation to this, Fran suggested that while shooting blank boss is useful for practising technique, the practice involves avoiding the fear of shooting at a target face - and perhaps even induces fear when an archer then competes.

'I think blank boss isn't that helpful unless you're working on your technique. Because really like, it's a safety net because you can go "well I'm not going to miss", whereas if I just go to a target and practice, [...] I'm practising to get away from that so I'm facing the fear. So, I just think if I shoot more at a face in practice and then go to a competition, I'm not thinking "I've only really done blank boss". [...] I feel more fearful if I'm just shooting at blank boss and then go to a competition.'

It seems that blank boss may lull archers into a false sense of security which then makes it more difficult for them to shoot at a target face and may ultimately increase the 
archer's anxiety when competing. Jessica attempted a similar method to blank boss by closing her eyes when shooting so she could not see the target face.

‘... one was closing my eyes, pulling up with my eyes shut, I would pull up and as soon as my eyes opened, that was it, it was gone.'

This technique is similar to blank boss in the sense that it is only useful until the archer has to aim at the target once more. This suggests that when experiencing target panic, individuals do not necessarily have an issue with technique. Rather, it seems that when moving on from blank boss or eyes closed shooting, to looking at the target face, archers experience a build-up of anticipation and anxiety, and a recurrence of target panic. This is further illustrated by Julia.

'I might think right, draw up for five of them and put my hand on the trigger and then on the last one, try and draw up and do it and execute the shot... Well I already feel more anxious. I can come up confidently on the five but then on that one I have a different feeling when I'm drawing up.'

Due to avoiding the anxiety-inducing element of the shot (putting her thumb on the trigger and releasing the shot by pressing the trigger) on the five practice arrows, an unnecessary build-up to the sixth arrow has occurred. This build-up induces anticipation and increased anxiety regarding executing the shot and consequently exacerbates her target panic. Therefore, practices such as 'blank boss' and training with eyes closed need further consideration.

Jessica was the only participant to describe an effective coping strategy for managing target panic- hypnosis:

'[Hypnosis has had] an effect in the sense of it does make you concentrate, I'm more driven and focused, I'm more relaxed in my approach to things, I'm more confident, erm and that carries through the archery.' 
Jessica describes hypnosis as a tool for improving overall confidence and as a resource to develop relaxation techniques, similar to meditation. By tackling her anxiety and under-confidence directly, this helped her to successfully tackle her target panic.

The ability to manage target panic and associated anxiety may be related to athlete experience. It was evident in the data that those athletes with more experience who competed at national or international competitions were more likely to experience target panic during the latter stages of competition (e.g. during the last shot, as highlighted by Julia earlier). However, less experienced archers spoke about target panic impacting multiple areas of their performance, including during training and in early shots during competitions. Thus, more experienced archers seemed better able to cope with their target panic, remaining in control of their shot for the majority of the time. This might be related to expectations relating to the outcome of the shot they are making where for experienced archers; the significance of the final shot can determine if a medal is secured. On the other hand, for less experienced archers like for Jessica and David, overcoming target panic might depend on improving confidence and tackling underlying anxieties. However, further research would need to be carried out to develop this line of thought.

Nevertheless, the findings from this theme suggests that traditional methods for managing target panic, such as blank boss, might not be effective because they do not tackle the psychological causes of the problem. It appears that archers who experience target panic have associated difficulties with anxiety linked to their confidence and expectations surrounding their performance. Thus, target panic can be described as a complex disorder which manifests through both physical and physiological characteristics, but is underpinned by control and anxiety, and reinforced through pressure to perform. 


\section{Discussion}

Performance blocks are a sudden loss of skill that had previously been effortless (Bennett et al, 2015). The objective of this study was to explore archers' experiences of target panic, an archery-specific performance block, in response to the research question, "how do archers experience and conceptualise target panic?". The themes presented demonstrate its complex nature. The first superordinate theme was 'Focussing on the Outcome of a Shot', within which archers partially attributed their target panic to their focus on the outcome of their shots (i.e. the results). The archers then developed significant expectations surrounding their performance or were acutely aware of the expectations of others. This was explored within the sub-theme 'Expectation to Perform'. These expectations then led to the archers attempting to manage their anxiety by increasing control over their shots which ultimately reduced their performance ability - this was discussed within the sub-theme 'Need for Control'. The second superordinate theme was 'Loss of Control' which denotes how archers with target panic lose control over their shot sequence. The participants explored their loss of control and often related it to significant previous events which exacerbated their anxiety and led to them avoiding executing their shots. These challenges were discussed within the sub-

themes 'Avoidance Mediated Through Significant Past Events' and 'Growing Anxiety'. Finally, the third superordinate theme was 'Regaining Control'. This theme relates to how the archers attempted to cope with their target panic and regain control over their technique.

When archers begin to experience performance related anxiety through high self-expectation, or the expectations of others, the outcome of each shot becomes a core focus. The need to control the shot to achieve the expected outcome then leads to 
inward-thinking, reinforcing the performance pressure, increasing anxiety and resulting in avoidant performance-related behaviours, manifesting in the physical and psychological manifestation of target panic, which is supported by the work of Jones, Meijen, McCarthy \& Sheffield, 2009. Jackson, Ashford \& Norsworth (2006), in their studies of hockey and soccer players report similar findings, which align with self-focus theories (Baumeister, 1984; Lewis \& Linder, 1997). Specifically, Jackson et al's (2006) experimental work showed that increased pressure alongside a skill-focus results in increased likelihood of failure to perform. While their work paid attention to skill-focus, the results of this study show that for archers, it might be that outcome-focused performance precedes a focus on skill or technique, demonstrated here through an increased desire to control the shot. These elements increase pressure to perform leading to 'choking' or task failure (Clarke, Sheffield \& Akehurst, 2015).

Further, the high self-criticality of participants in this study, led to the internalisation of performance failure as a representation of personal self-concept and their identification as an athlete (Koivula, Hassmén and Fallby, 2002), contributing to their athletic identity. Athletic identity is an important consideration because it is often related to an athlete's self-concept, which is closely tied to athletic performance (Sparkes, 1998). This may be problematic when athlete performance does not meet an athletes self-defined expectation, as demonstrated in the findings presented here. This may then contribute to the development of target panic, as well as impacting self-esteem and psychological wellbeing (Neff, 2002). This is something highlighted by Philippen \& Lobinger (2012), who also highlight the significant negative emotional impact on golfers who experience the yips. They highlight that for most of their participants, feelings of anger, fear and disappointment in relation to performance outcomes were common. 
Outcome-based expectations were a source of anxiety for participants in this study. While the expectations of others were not explicit, the internalisation of what spectators, coaches and family members might expect increased anxiety and diminished confidence in the ability to achieve the intended outcomes, similar to the experiences of the golfers interviewed in Philippen and Lobinger's (2012) study. Distraction theories suggest that an increase in expectation creates a distraction that shifts athletes' focus to task-irrelevant cues such as concerns about the situation and its consequences (Eysenck et al, 2007), and this seemed to be the case for the archers in this study. As a result, task execution and state-anxiety compete for attention, negatively influencing performance and contributing to the onset of performance blocks (Clarke, Sheffield and Akehurst, 2015; Eysenck et al, 2007;).

Research has indicated that anxiety can be reduced through increased control over a potentially threatening situation (Jones, Meijen, McCarthy and Sheffield, 2009), however for participants of this study, this led to increased performance anxiety. This suggests that those prone to target panic might be characterised by perfectionism which hinders performance, leading to a discrepancy between expectations and outcomes (Flett and Hewitt, 2005). Indeed, through attempting to control shot execution and outcome, the archers experienced loss of control, representing a conflict between the archers' intentions, their ability to manage anxious thoughts and their physical capabilities during anxiety-driven events (Jones et al., 2009) and consequently triggers the physical anxiety response of target panic.

Findings highlighted that significant past events might act as a trigger for the anxiety associated with performance blocks. The effect of these events for the archers was not dissimilar to anxiety-related disorders, which has similarly been reported by Bennett et al (2015). Events associated with anxiety frequently involved archers 
experiencing or witnessing serious injury or threat, inducing fear and helplessness when performing under pressure. Participants consequently experienced physiological reactivity to certain stimuli and displayed avoidant behaviours regarding the stimuli related to the significant event.. This suggests that unresolved negative past events might induce an unconscious anxious state which is triggered in times of increased stress. Indeed, Bennet, Bickley, Vernon, Olusoga and Maynard (2017) acknowledge the link between significant past events and performance blocks and suggest the use of eye movement desensitisation and reprocessing (EMDR) as an effective treatment for performance blocks. For the archers in this study, the tendency was to avoid feelings associated with significant past events, manifesting as target panic. This supports the view that avoidance motivation is associated with high anxiety and low performance (Roberts, Treasure and Conroy, 2007) and that negatively construed possibilities are linked to moving away from the stimulus (Elliot \& Covington, 2001). Nevertheless, the findings do indicate that there is a need for relevant and effective interventions for target panic to be developed, which allow archers to regain control over their performance.

Participants discussed the strategies they had used to manage target panic, which focussed on regaining control over their shooting behaviour. Some archers attempted to avoid internalising their perceived failure but found this difficult and remained critical of their ability to overcome target panic. This highlights the significant impact of performance blocks on archers' self-efficacy, self-worth and general wellbeing (Bennett, Rotherham, Hays, Olusoga, \& Maynard, 2016) but also highlights the significant psychological component relating to performance blocks, which is also noted by Philippen and Lobinger (2012). Interestingly, for the archers in this study, the most common strategy to overcome these difficulties was not one which related to 
psychological reprocessing of the anxiety-related cognitions, but rather focused on technical ability - blank boss. This practice of shooting with no face on the target, or with eyes closed is typically used by archers to improve their technique but is also widely recommended as a treatment for target panic. While no literature exists in relation to the effectiveness of blank boss as a treatment for performance blocks, the findings here suggest that this practice is ineffective. Treatments which focus on the underlying anxiety manifesting in performance blocks, like EMDR, may be more successful (Bennet, Bickley, Vernon, Olusoga and Maynard, 2017). Indeed, within this study, the only successful strategy for overcoming target panic related to the use of hypnosis, designed to relieve stress and improve self-confidence (Pates, Cummings and Maynard, 2002), however more robust research exploring the effectiveness of interventions to treat target panic, and indeed performance blocks more generally, is needed (Bennett et al, 2017). This research does suggest that one avenue which might be worth more consideration could be therapies which focus on decreasing anxiety and increasing confidence in relation to performance. This may help to target the psychological factors related to performance failure, like low self-esteem, and rather build resilience (Newmark and Bogacki, 2005).

\section{Conclusion}

This study aimed to better understand the manifestation of performance blocks in archers and has gone some way to furthering understanding by exploring the lived experiences of target panic. It demonstrated the complex nature of target panic by identifying antecedents, such as an outcome-focus and negative past events; the manifestation of target panic through anxiety and avoidant behaviours; and the strategies which might be adopted to regain control and manage target panic. The 
findings contribute to insight for archers, coaches and sport psychologists, who may wish to further their own knowledge and develop effective techniques to prevent/manage performance blocks in archers. Whilst the findings of this study do not allow for conclusions to be drawn about what successful interventions might entail, it presents a comprehensive understanding of target panic and its manifestations, which will allow for more research to be carried out which focuses specifically on interventions. Due to the negative impact of target panic, not only on performance, but on athlete wellbeing and their experience of sport, future research should concentrate on understanding effective coping mechanisms to manage performance blocks. Specifically, coaches and sport psychologists should consider the development of interventions which support archers in overcoming problems relating to anxiety, selfcriticality and low confidence, which may lead to the onset, and prolong the effect of performance blocks.

\section{References}

Baumeister, R. F. (1984). Choking under pressure: self-consciousness and paradoxical effects of incentives on skilful performance. Journal of personality and social psychology, 46(3), 610 .

Baumeister, R. F., Hutton, D. G., \& Cairns, K. J. (1990). Negative effects of praise on skilled performance. Basic and Applied Social Psychology, 11(2), 131-148.

Baumeister, R. F., \& Showers, C. J. (1986). A review of paradoxical performance effects: Choking under pressure in sports and mental tests. European Journal of Social Psychology, 16(4), 361-383. 
Bawden, M., \& Maynard, I. (2001). Towards an understanding of the personal experience of the 'yips' in cricketers. Journal of Sports Sciences, 19(12), 937953.

Bennett, J., Bickley, J., Vernon, T., Olusoga, P., \& Maynard, I. (2017). Preliminary evidence for the treatment of performance blocks in sport: the efficacy of EMDR with graded exposure. Journal of EMDR Practice and Research, 11(2), 96-110.

Bennett, J., Hays, K., Lindsay, P., Olusoga, P., \& Maynard, I. W. (2015). Yips and lost move syndrome: exploring psychological symptoms, similarities, and implications for treatment. International Journal of Sport Psychology, 46(1), 6182.

Bennett, J., Rotherham, M., Hays, K., Olusoga, P., \& Maynard, I. (2016). Yips and lost move syndrome: Assessing impact and exploring levels of perfectionism, rumination, and reinvestment. Sport and Exercise Psychology Review, 12(1).

Bennett, J., \& Maynard, I. (2017). Performance blocks in sport: Recommendations for treatment and implications for sport psychology practitioners. Journal of Sport Psychology in Action, 8(1), 60-68.

Clarke, P., Sheffield, D., \& Akehurst, S. (2015). The yips in sport: A systematic review. International Review of Sport and Exercise Psychology, 8(1), 156-184.

Crampton, J., \& Adams, R. (1995). Expert errors. Sports Coach, 18, 28-28.

Dhungana, S., \& Jankovic, J. (2013). Yips and other movement disorders in golfers. Movement Disorders, 28(5), 576-581.

Elliot, A. J., \& Covington, M. V. (2001). Approach and avoidance motivation. Educational Psychology Review, 13(2), 73-92. 
Eysenck, M. W., Derakshan, N., Santos, R., \& Calvo, M. G. (2007). Anxiety and cognitive performance: attentional control theory. Emotion, 7(2), 336.

Flett, G. L., \& Hewitt, P. L. (2005). The perils of perfectionism in sports and exercise. Current directions in psychological science, 14(1), 14-18.

Jackson, R. C., Ashford, K. J., \& Norsworthy, G. (2006). Attentional focus, dispositional reinvestment, and skilled motor performance under pressure. Journal of Sport and Exercise Psychology, 28(1), 49-68.

Jones, M., Meijen, C., McCarthy, P. J., \& Sheffield, D. (2009). A theory of challenge and threat states in athletes. International Review of Sport and Exercise Psychology, 2(2), 161-180.

Kidwell, J. (2004). Instinctive Archery Insights. (2nd ed.). Jay Kidwell.

Koivula, N., Hassmén, P., \& Fallby, J. (2002). Self-esteem and perfectionism in elite athletes: effects on competitive anxiety and self-confidence. Personality and individual differences, 32(5), 865-875.

Lewis, B. P., \& Linder, D. E. (1997). Thinking about choking? Attentional processes and paradoxical performance. Personality and Social Psychology Bulletin, 23(9), 937-944.

Marquardt, C. (2009). The vicious circle involved in the development of the yips. International Journal of Sports Science \& Coaching, 4(1_suppl), 67-88.

Maxwell, J. P., Masters, R. S. W., \& Eves, F. F. (2000). From novice to no know-how: A longitudinal study of implicit motor learning. Journal of sports sciences, 18(2), 111-120.

McFarlane, B. (1990). Correct the lead leg with line hurdling. Track and Field Quarterly Review, 90, 25. 
Neff, K. (2003). Self-compassion: An alternative conceptualization of a healthy attitude toward oneself. Self and identity, 2(2), 85-101.

Newmark, T. S., \& Bogacki, D. F. (2005). The use of relaxation, hypnosis, and imagery in sport psychiatry. Clinics in sports medicine, 24(4), 973-977.

Pates, J., Cummings, A., \& Maynard, I. (2002). The effects of hypnosis on flow states and three-point shooting performance in bastketball players. The Sport Psychologist, 16(1), 34-47.

Pietkiewicz, I., \& Smith, J. A. (2014). A practical guide to using interpretative phenomenological analysis in qualitative research psychology. Psychological Journal, 20(1), 7-14.

Philippen, P. B., \& Lobinger, B. H. (2012). Understanding the yips in golf: Thoughts, feelings, and focus of attention in yips-affected golfers. The Sport Psychologist, 26(3), 325-340.

Rice, S. M., Purcell, R., De Silva, S., Mawren, D., McGorry, P. D., \& Parker, A. G. (2016). The mental health of elite athletes: a narrative systematic review. Sports Medicine, 46(9), 1333-1353.

Roberts, G. C., Treasure, D. C., \& Conroy, D. E. (2007). Understanding the dynamics of motivation in sport and physical activity: An achievement goal interpretation. Handbook of Sport Psychology, Third Edition, 1-30.

Singer, R. N. (2001). Preperformance state, routines, and automaticity: What does it take to realize expertise in self-paced events?. Journal of Sport and Exercise Psychology, 23(4), 359-375.

Smith, A. M., Adler, C. H., Crews, D., Wharen, R. E., Laskowski, E. R., Barnes, K., ... \& Sorenson, M. C. (2003). The 'Yips' in golf. Sports Medicine, 33(1), 13-31. 
Smith, B., \& McGannon, K. R. (2018). Developing rigor in qualitative research: Problems and opportunities within sport and exercise psychology. International Review of Sport and Exercise Psychology, 11(1), 101-121.

Smith, J. A. (2004). Reflecting on the development of interpretative phenomenological analysis and its contribution to qualitative research in psychology. Qualitative research in psychology, 1(1), 39-54.

Smith, J., Flowers, P., \& Larkin, M. (2009). Interpretative Phoneomological Analysis: theory, method and research. London: Sage

Sparkes, A. C., \& Smith, B. (2013). Qualitative research methods in sport, exercise and health: From process to product. Routledge.

Sparkes, A. C. (1998). Athletic identity: An Achilles' heel to the survival of self. Qualitative Health Research, 8(5), 644-664.

Thomas, K. (2008) The Secret Curse of Expert Archers. New York Times (2008, Aug 1), retrieved from http://www.nytimes.com

Weiss, S. M., \& Reber, A. S. (2012). Curing the dreaded "Steve Blass disease". Journal of Sport Psychology in Action, 3(3), 171-181. 